\title{
Handbook of Research \\ Methods in Tourism \\ Quantitative and Qualitative Approaches
}

Edited by Larry Dwyer, Alison Gill and Neelu Seetaram 
Handbook of Research Methods in Tourism

'This is an excellent book which significantly contributes to tourism research and education. It takes a rigorous yet readable style to address twentyfive of the most pertinent quantitative and qualitative techniques applied in tourism research. The book will appeal to a wider readership of social scientists as well as to scholars of tourism as each chapter provides a thorough overview and explanation of the techniques irrespective of their tourism application.'

- Dimitrios Buhalis, Bournemouth University, UK

This insightful book explores the most important established and emerging qualitative and quantitative research methods in tourism. The authors

provide a detailed overview of the nature of the research method, its use in tourism, the advantages and limitations, and future directions for research.

Each chapter is structured to provide information on: the nature of the technique and its evolution; background and types of problems that the technique is designed to handle; applications of the technique to tourism, including discussion of studies that have used the technique and their findings; advantages and limitations of the technique conceptually and technique in tourism research.

Handbook of Research Methods in Tourism will appeal to social scientists, students as well as researchers in tourism who use quantitative and qualitative research techniques.

Larry Dwyer is Professor of Travel and Tourism Economics at the University of New South Wales, Australia; Alison Gill is at Simon Fraser University, Canada and Neelu Seetaram is at Bournemouth University, UK.

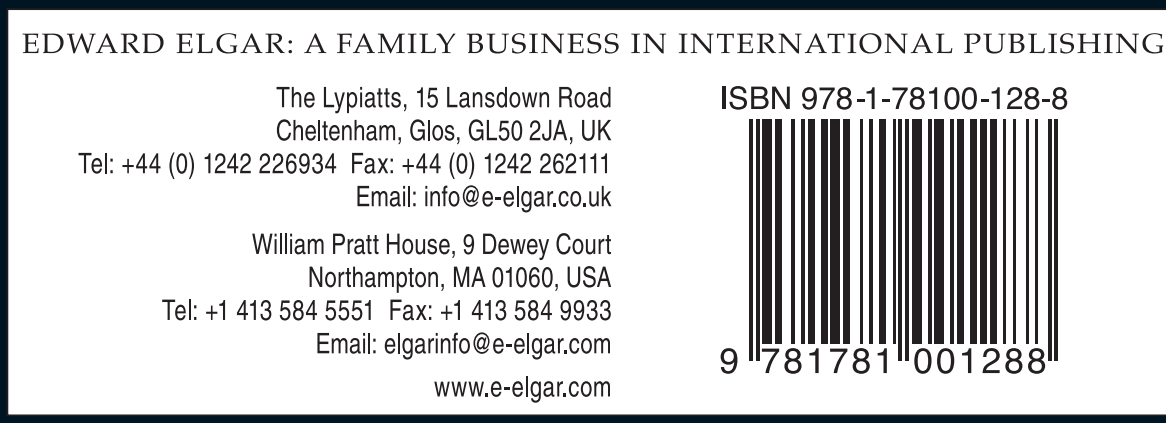

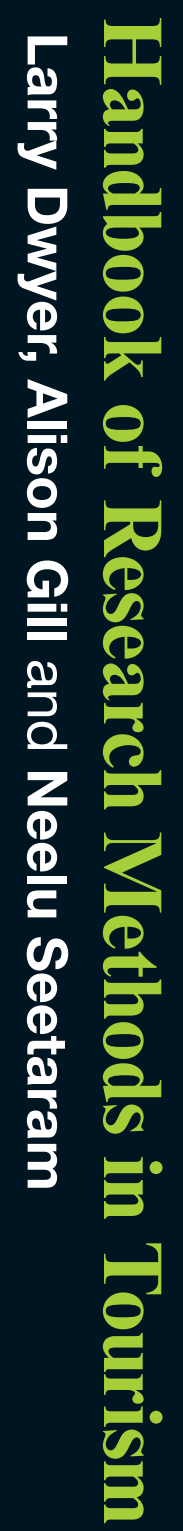

Handbook of Research Methods in Tourism

\section{Quantitative and Qualitative Approaches}

Edited by Larry Dwyer, Alison Gill and Neelu Seetaram

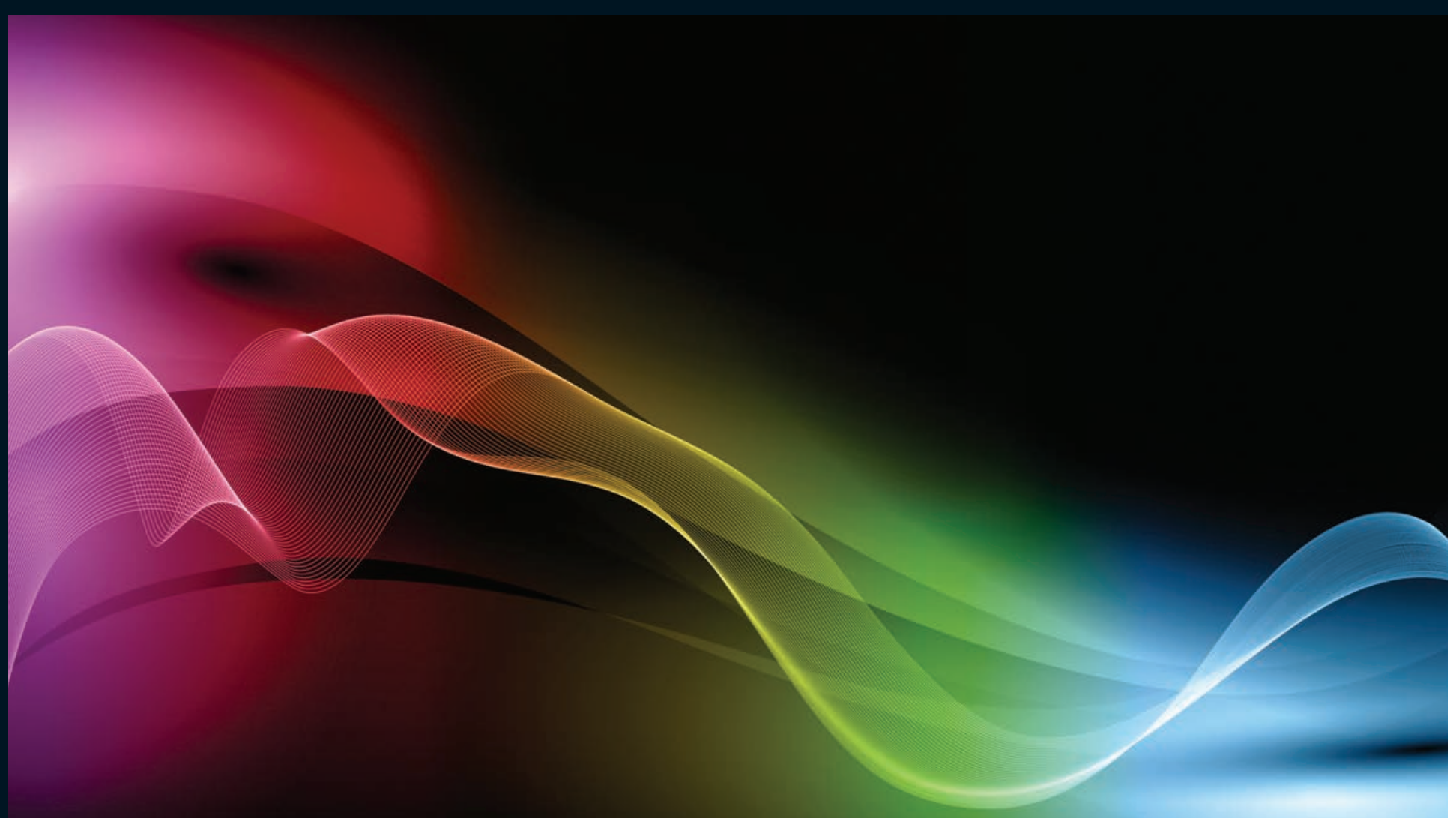

